\title{
EDITORIAL
}

\section{Chemical communication by infochemicals}

\author{
Ursula Klaschka
}

Received: 3 May 2009 / Accepted: 5 May 2009/Published online: 15 May 2009

(C) Springer-Verlag 2009

\section{Chemical communication}

Homo sapiens depends very much on visual and acoustic stimuli to get along in every day life whereas the role of odours is considered as of secondary importance. This is very different for most environmental organisms who live in an "odour world" and depend strongly on chemical stimuli to learn about their biotic and abiotic environments. These chemical cues are called infochemicals. The chemical environment plays a prevalent role for the fine tuning of articles that increase the survival of a species, such as searching food or shelter, reproducing, optimizing the survival conditions for the offspring or avoiding potential predators. Especially in aquatic systems, the dominance of the chemical sense has clear advantages as it allows to perceive stimuli at night as well as in turbid water, and visual obstacles are no hindrance for perception. The complexity and sophistication of the chemical communication systems are difficult to imagine from the human perspective (Burks and Lodge 2002; Brönmark and Hansson 2000; Dodson et al. 1994; Klaschka 2008a, b).

Natural infochemicals are usually odorants. Therefore, the knowledge of the basic steps of the reaction cascade of the olfactory perception is needed to understand the chemical communication by infochemicals. A generalized scheme is depicted in Fig. 1. Infochemicals are released by a biotic or abiotic sender. They may find the olfactory epithelium of a receiver where they can bind to specific odorant-binding proteins leading to the formation of an

U. Klaschka $(\bowtie)$

University of Applied Sciences Ulm,

Prittwitzstr. 10,

89075 Ulm, Germany

e-mail: klaschka@hs-ulm.de electrical signal which is transduced to the central nervous system evoking the perception. The perception of an infochemical can lead to morphological, physiological or behavioral reactions of the receiver or even to changes on population levels. Internal factors (such as age, sex, activity state) and external factors (such as time of the day or the year, temperature) can influence the emission of infochemicals by the sender as well as the various steps of the reaction cascade in the receiver.

\section{Anthropogenic infochemicals and the infochemical effect}

We have only begun to understand the relevance of chemical communication. Environmental organisms are exposed to a sophisticated blend of natural infochemicals where subtle changes can interfere with this elaborate system and may lead to far reaching direct and indirect effects. Sublethal effects due to disturbed chemical communication may be even more detrimental for the survival of a species than toxic effects. Reduced food uptake, ignoring the predator, impaired mating behaviour or other inappropriate responses can lead to population declines, even if the individuals are perfectly healthy. There are strong evidences that anthropogenic compounds, such as fragrances used in perfumes, cosmetics or cleansing products interfere with the chemical communication of environmental organisms. This effect was discovered only recently and is called infochemical effect. It describes that anthropogenic substances can influence an organism so that it perceives its chemical environment differently. The anthropogenic substances responsible for the infochemical effect are called anthropogenic infochemicals. They might interfere at each step of the chemosensory signal transduc- 


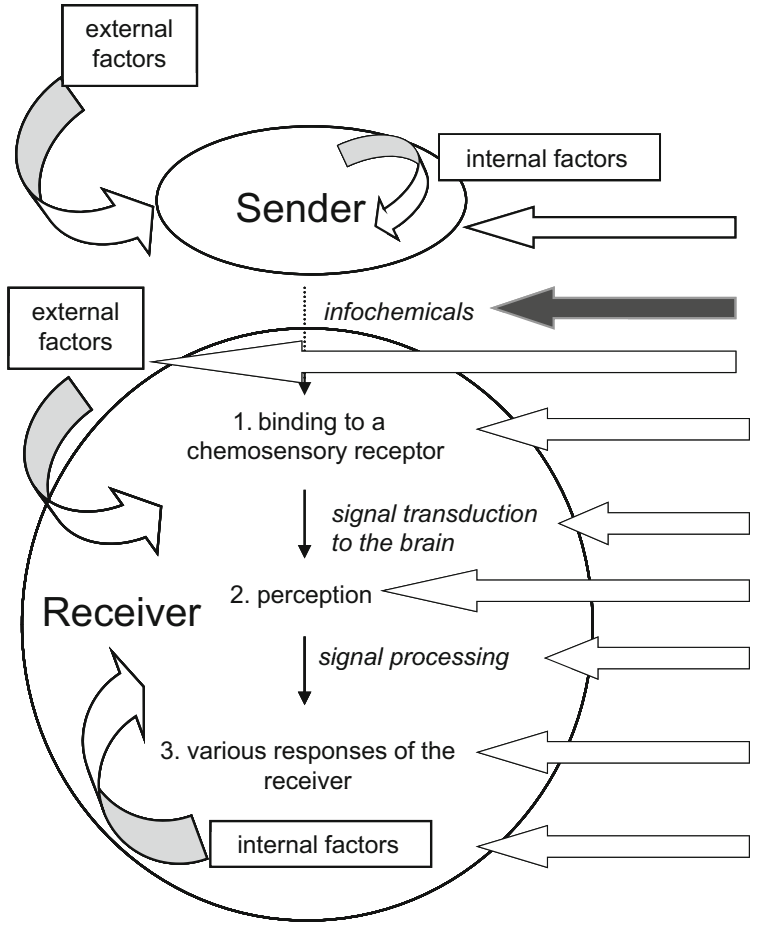

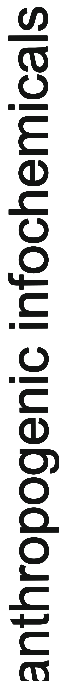

Fig. 1 Simplified model of the reaction chain of the chemical communication by infochemicals. The possible sites of action of anthropogenic infochemicals are indicated by arrows

tion pathway described in Fig. 1 and indicated by arrows. It is very important to note that the very low concentrations which can be responsible for the infochemical effect are in the ranges of environmental concentrations of many anthropogenic contaminants.

\section{Fragrances as infochemicals}

Anthropogenic infochemicals can be of the same chemical nature as natural infochemicals. A slight increase of the environmental concentration by anthropogenic discharges can increase the natural concentration considerably and might deceive the respective receiver organisms who depend on this infochemical. Substances listed in Table 1 are commonly used fragrances which were identified as natural infochemicals by various research groups.

Fragrances of the same chemical identity as natural infochemicals represent the simplest mode of action of anthropogenic infochemicals pictured by the black arrow in Fig. 1. Also substances with different structures than the natural infochemicals might interfere at many sites in the reaction cascade as shown by the arrows in Fig. 1 . Anthropogenic infochemicals could compete with natural infochemicals on the odorant-binding proteins, they could poison the receptors or neurons, they could act as background concentrations, they could interfere with the second messenger pathways, they could influence the capacity of the organisms to perceive odors, they could interfere in the development of the functional chemosensory tissue. Anthropogenic infochemicals could also affect the reaction patterns of the receivers (Klaschka 2009, this issue).

\section{Conclusions}

Knowing the importance of the very sophisticated communication system via infochemicals, it seems obvious that anthropogenic infochemicals may have a deleterious effect.

Table 1 Some compounds used in perfumes and their roles in nature (Harborne 1993; Polya 2003) (see Klaschka and Kolossa-Gehring 2007) $\begin{array}{ll}\text { Compound and CAS No. } & \begin{array}{l}\text { Role as infochemical } \\ \text { in nature }\end{array}\end{array}$

Anethole 104-46-1 and Anisaldehyde 135-02-4 ; 123-11-5

Benzaldehyde 100-52-7

Benzoic Acid 65-85-0

D-Bornylacetate 5655-61-8

Camphene 79-92-5

Camphor 76-22-2

Citral 5392-40-5; 624-15-7, Linalool 78-70-6 and Terpinyl acetate $80-26-2$

Citral 5392-40-5; 624-15-7 and Citronellal 106-23-0

p-Cresol 106-44-5

Isopentenylacetate 5205-07-2

Methylisoeugenol 93-16-3

Ocimene 13877-91-3

alpha, beta-Pinene 7785-26-4; 18172-67-3

\section{Salicylaldehyde} 90-02-8

Terpinolene 586-62-9

Tridecanone 593-08-8

\section{food attractant}

sex pheromone

phytoalexin

sex pheromone

food attractant

food attractant

allelopathy

insect repellant

antiseptic

food attractant

signal for egg deposition

defence

antiseptic

defence

warning pheromones

food attractant

food attractant

signal for egg deposition

repellent

defence

allellopathy repellent

defence

hygiene (to keep the body surface clean and allow breathing under water)

food attractant

warning pheromones

repellant

various other responses 
The ecotoxicological standard tests used presently may not cover such important impacts of chemicals released into the environment. A systematic analysis is needed to find out whether and to what extent anthropogenic chemicals such as fragrances interfere with the chemical communication in natural ecosystems (Klaschka 2009, this issue). The research about the infochemical effect is only at the beginning.

\section{References}

Brönmark C, Hansson LA (2000) Chemical communication in aquatic systems: an introduction. Oikos 88:103-109

Burks RL, Lodge DM (2002) Cued in: advances and opportunities in freshwater chemical ecology. J Chem Ecol 28:1901-1917
Dodson SI, Crowl TA, Peckarsky BL, Kats LB, Covich AP, Culp JM (1994) Non-visual communication in freshwater benthos-an overview. J N Am Benthol Soc 13:268-282

Harborne JB (1993) Introduction to ecological biochemistry. Academic, London

Klaschka U (2008a) The infochemical effect-a new chapter in ecotoxicology. Environ Sci Pollut Res 15(6):448-458

Klaschka U (2008a) Odorants-potent substances at minor concentrations. The ecological role of infochemicals. In: Kümmerer $\mathrm{K}$ (ed) Pharmaceuticals in the environment. Sources, fate, effect and risks, 3rd edn. Springer, pp 305-320

Klaschka U (2009) A new challenge: development of test systems for the infochemical effect. Environ Sci Pollut Res 16(4):370-388

Klaschka U, Kolossa-Gehring M (2007) Review article. Fragrances in the environment: pleasant odours for nature? Environ Sci Pollut Res 14(Special Issue 1):44-52

Polya G (2003) Biochemical targets of plant bioactive compounds. A pharmacological reference guide to sites of action and biological effects. Taylor and Francis, London and New York 